\title{
Transition metal-free homologative cross-coupling of aldehydes and ketones with geminal bis(boron) compounds
}

\author{
Thomas C. Stephens and Graham Pattison* \\ Department of Chemistry, University of Warwick, Gibbet Hill Road, Coventry, CV4 7AL, UK. \\ Supporting Information Placeholder
}

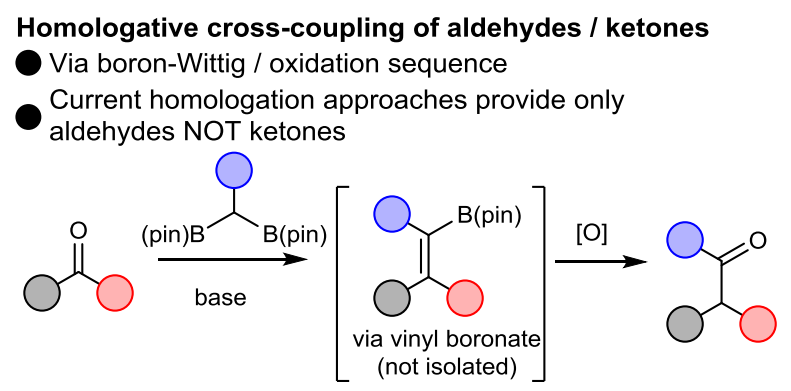

\begin{abstract}
We report a transition metal-free coupling of aldehydes and ketones with geminal bis(boron) building blocks which provides the coupled, homologated carbonyl compound upon oxidation. This reaction not only extends an alkyl chain containing a carbonyl group, it also simultaneously introduces a new carbonyl substituent. We demonstrate that enantiopure aldehydes with an enolizable stereogenic centre undergo this reaction with complete retention of stereochemistry.
\end{abstract}

A range of coupling processes, both metal-catalyzed and metal-free, are transforming the way chemists build molecules. Transition metal-free coupling processes ${ }^{1}$ are of particular attraction due to very stringent requirements for low ppm values of toxic transition metal residues in pharmaceutical products. As a result, a series of such transition metal-free coupling processes are beginning to emerge, using in particular readily available building blocks such as organoboron compounds. 2,3

One class of organoboron building block which is seeing significant recent attention are geminal-bis(boronates). These are air- and moisture-stable compounds of which diverse substituted derivatives can be easily prepared. Bis[(pinacolato)boryl]methane, which can be used as a precursor for many substituted geminal bis(boron) compounds by deprotonation and alkylation, ${ }^{4}$ is now commercially available or can be prepared easily in one step from dibromomethane. ${ }^{5}$ Several other methods have been reported for the synthesis of these compounds, including borylation of geminal dibromides, ${ }^{6}$ hydroboration of alkynes and vinylboronates, ${ }^{7} \mathrm{C}-\mathrm{H}$ borylation $^{8}$ and the diborylation of $N$-tosylhydrazones, diazoalkanes and carbonyl compounds. ${ }^{9}$ The geminal bis(boronate) building blocks have been used in several catalytic crosscoupling processes including Suzuki-Miyaura crosscoupling, ${ }^{10}$ additions to carbonyl compounds ${ }^{11}$ and allylic substitution reactions ${ }^{12}$ amongst other transformations. ${ }^{13}$

One key reaction of interest regarding geminal bis(boronates) is the boron-Wittig reaction, which is the reaction of a deprotonated geminal bis(boronate) with an aldehyde or ketone to provide a vinyl boronate. ${ }^{14}$, These reactions often proceed with a very high degree of stereocontrol over double bond geometry.

The key to our general synthetic strategy was the realization that oxidation of this vinyl boronate will afford a homologated aldehyde or ketone. Carbonyl compounds have proven to be some of the key mainstays of organic synthesis over the years, being found in a broad range of biologically active compounds as well as being key substrates for the synthesis of many alcohols, heterocycles and enolate condensation products.

Homologation reactions of carbonyl compounds are extremely useful as they extend a chain by one carbon and may convert a readily accessible carbonyl compound into its much more valuable homolog. The homologation of aldehydes and ketones to one-carbon-extended aldehydes is well known, and is generally achieved by either Wittig reactions with alkoxy-substituted phosphonium salts (via hydrolysis of the enol ether formed), or epoxide formation with a sulfonium ylid followed by acid-mediated Meinwald rearrangement to the homologated aldehyde. ${ }^{15}$ However, a homologative crosscoupling process in which an aldehyde or ketone not only undergoes a one-carbon chain extension, but a new ketone substituent is simultaneously introduced is not currently available.

Here we present a versatile homologative coupling reaction which allows the introduction of a new ketone substituent in tandem with carbonyl chain-extension. This process is formally an umpolung coupling of two carbonyl compounds as the geminal bis(boron) component can be readily derived from an aldehyde via its tosylhydrazone. 
Scheme 2: Homologative cross-coupling of aldehydes and ketones with geminal bis(boron) compounds [a] dr $>19: 1$. Also contains $18 \%$ unoxidized vinyl boronate.

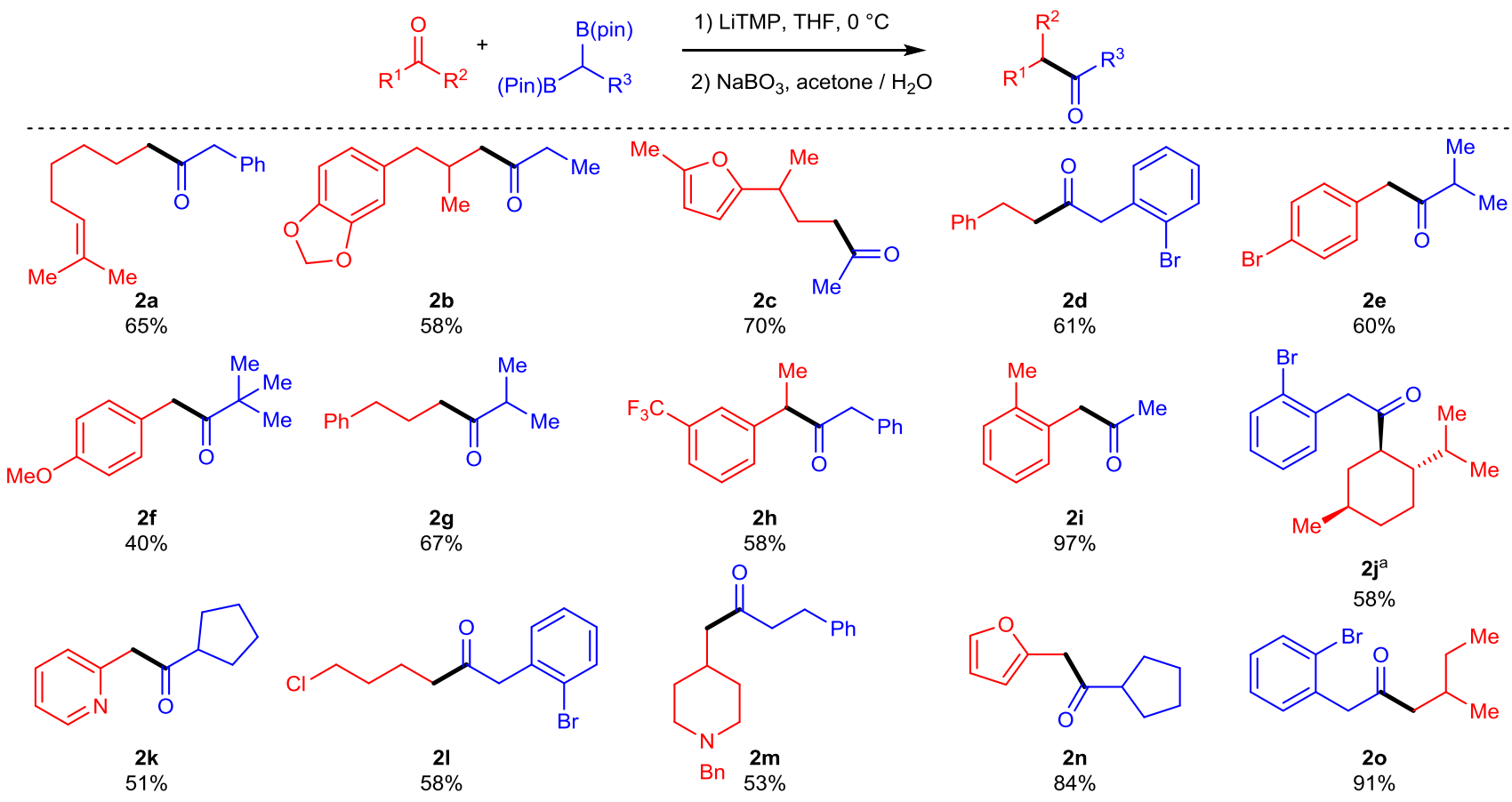

This strategy can be used in iterative sequences, as the homologated carbonyl products can then be subjected to further boron-Wittig processes to add in an additional subunit and extend the chain. In addition, the intermediate compounds are amenable to the vast and well-established chemistry of vinyl boronates and aldehydes and ketones which should allow the rapid generation of a diverse range of functionalized products.

Conditions for the boron-Wittig reaction have been optimized recently, including in particular the use of LiTMP for the deprotonation of the geminal bis(boron) compound without competing nucleophilic attack at boron. ${ }^{16}$ However, conditions for the oxidation of alkenyl boronates to carbonyl compounds were less clear, and examples of such oxidations are surprisingly uncommon in the literature considering the ubiquity of oxidation of aryl- and alkyl-boron species in synthesis. ${ }^{14-c-c, 17} \mathrm{We}$ also aimed to develop this as a one-pot process, without need for isolation of the intermediate alkenylboron compound.

We chose to optimize our oxidation on cyclohexyl vinyl boronate 1, derived from cyclohexanone (Scheme 1). Of the range of oxidizing reagents studied we found aqueous sodium perborate in acetone to give the most consistent and cleanest results. ${ }^{18}$ It was important to find a solvent system in which solubility of both the oxidant and vinyl boronate was acceptable. Isolation and purification of the vinyl boronate was not necessary, and the procedure could be performed in a one-pot fashion with only a switch in solvent at the intermediate stage.

\section{Scheme 1. Optimized one-pot homologation conditions}

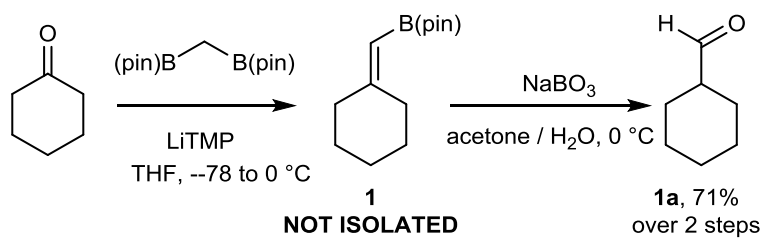

After boron Wittig reaction of carbonyl compound and lithiated geminal bis(boron) compound in THF was complete, the THF could be removed and replaced with acetone, followed by oxidation with aqueous sodium perborate.

It should be noted that on rare occasions alternative oxidants were required to homologate certain base-sensitive substrates which were not compatible with aqueous sodium perborate ( $\mathrm{pH} \sim 14)$. For example, one-carbon extension of aromatic aldehydes resulted in benzylic aldehydes which were susceptible to self-aldol processes under the basic reaction conditions. Here the use of oxone as oxidant (acidic) prevented the formation of these by-products, providing alternative conditions for the successful homologation of both base- and acidsensitive substrates. ${ }^{20}$

We then looked to develop these optimized conditions into a practical homologative coupling process using substituted geminal bis(boron) compounds. We were pleased to discover that our one-pot boron-Wittig / oxidation conditions could be easily extended to the homologative coupling of both aldehydes and ketones with substituted bis(boron) compounds (Scheme 2). A broad range of functional groups could be tolerated in this process, including alkenes, aromatic rings bearing both electron-withdrawing and electron-donating groups, heterocyclic rings including pyridines and furans, amines, halogen atoms and an acetal. Oxidation of tetrasubstituted alkenes arising from boron-Wittig reaction of ketones proceeded well, although did require longer reaction times, and the addition of extra equivalents of oxidant. The reaction was also effective to produce a ketone bearing a bulky tert-butyl group 2f.

Boron-Wittig / oxidation of menthone with 2-bromobenzyl geminal bis(boronate) provided the homologated ketone $\mathbf{2} \mathbf{j}$ with a high level of diastereoselectivity. Homologative coupling to form ketone $\mathbf{2 g}$ was performed on a $3 \mathrm{mmol}$ scale to demonstrate the reliability of this process. 


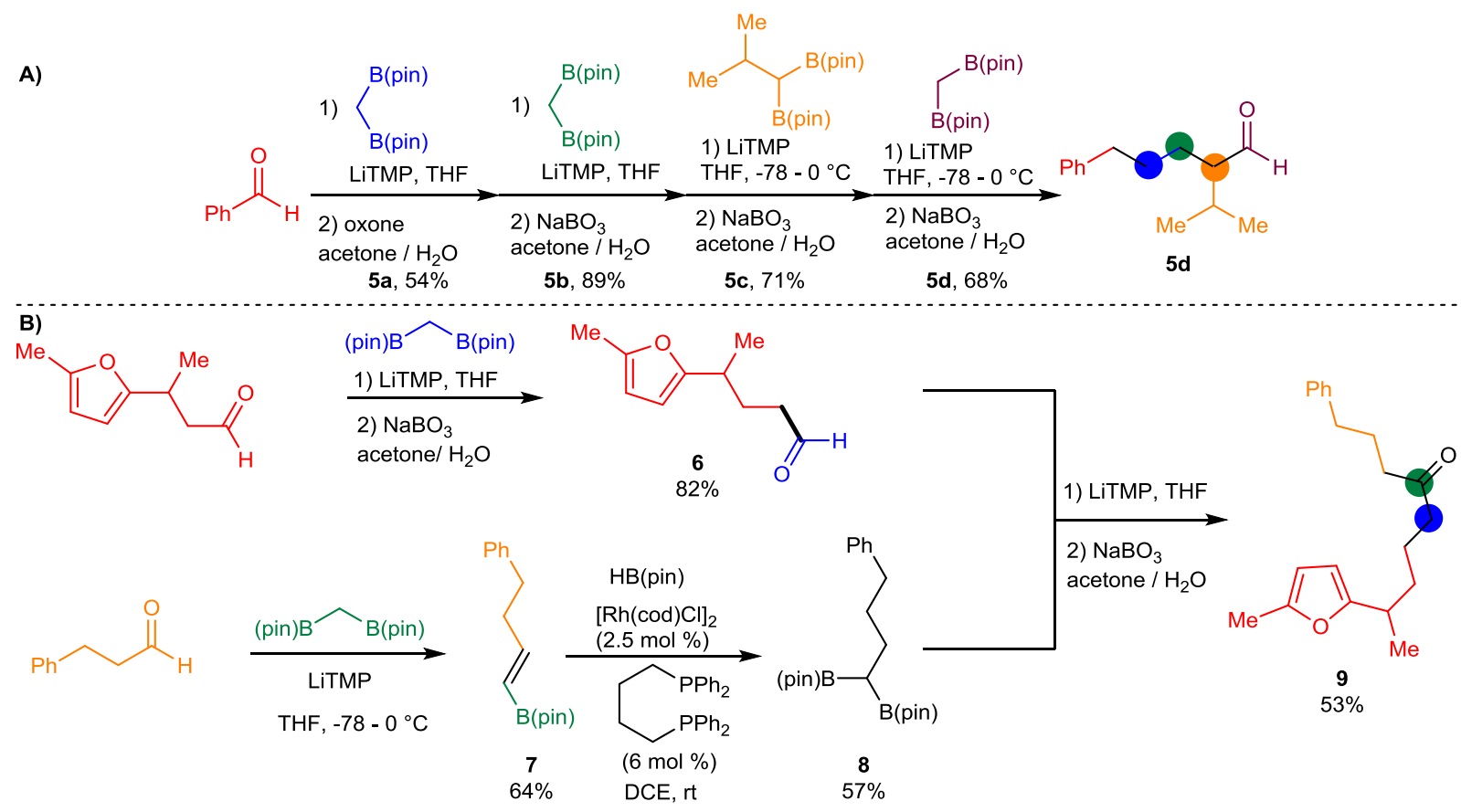

Impressively, a primary alkyl chloride $\mathbf{2 l}$ was also tolerated in this reaction despite $\mathrm{S}_{\mathrm{N}} 2$-alkylation of lithiated geminal bis(boron) compounds being a reliable procedure. In addition, reaction of chloroacetone yielded enone 3 (eq 1) which was formed by a boron-Wittig - oxidation - elimination sequence under the basic oxidation conditions with no competing nucleophilic displacement of chlorine. It would seem that the kinetics of addition of the deprotonated geminal bis(boron) compound to a carbonyl compound are significantly faster than in $\mathrm{S}_{\mathrm{N}} 2$ nucleophilic substitution of a primary alkyl chloride.

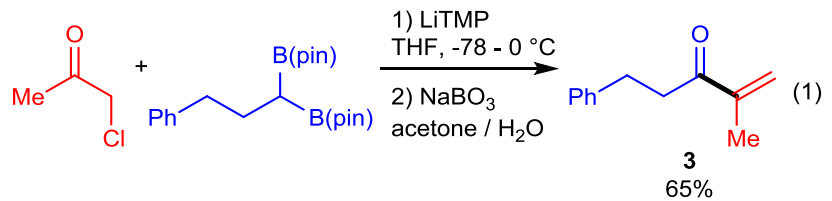

The use of a chiral enantiopure enolizable aldehyde in this reaction provided the homologative coupling product 4 with complete retention of stereochemistry (eq 2). That no racemization was observed has important mechanistic implications. Our base optimization studies allow us to estimate the $\mathrm{pK}_{\mathrm{a}}$ of geminal bis(boron) compounds to be between that of HMDS and TMP (i.e., $\mathrm{pK}_{\mathrm{a}}$ between 26 and 36 ), which would be sufficiently basic to lead to deprotonation of an enolizable aldehyde. That racemization is not observed would suggest that nucleophilic addition into an aldehyde is significantly kinetically favoured over deprotonation. The homologative coupling of readily-prepared enantiopure $\alpha$-stereogenic aldehydes will allow the stereogenic centre to be moved to a position where it may be more difficult to introduce with high enantioselectivity.

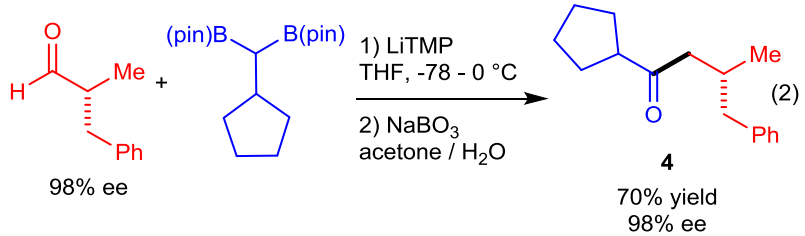

Of course, the product of all of these homologative coupling reactions is another carbonyl compound which will also be susceptible to boron-Wittig / oxidation sequences to undergo further chain extensions. This is an example of iterative synthesis, in which a larger molecule is constructed stepwise by the addition of one subunit in a sequential fashion. ${ }^{19}$ This strategy mimics the way nature often builds complex molecules and is particularly attractive to medicinal chemists and others who require the synthesis of large numbers of diverse analogs for testing. To demonstrate this concept we performed a 4-carbon chain extension of benzaldehyde to which proceeded efficiently with the introduction of an isopropyl group at a defined point in the chain (Scheme 3a).

One key attraction of this approach is that the vinyl boronate intermediates formed in the boron-Wittig reaction can be readily transformed into either of the starting materials required for boron-Wittig chemistry. Whilst we have shown already that oxidation yields a carbonyl derivative, it is also the case that hydroboration will provide the geminal bis(boronate) component. This will also allow components for cross-coupling to be assembled separately, and then to be combined together in a convergent fashion. To demonstrate this (Scheme $3 b$ ) we performed boron-Wittig chain extensions of 3-(5-methyl-2-furyl)butanal and hydrocinnamaldehyde, subjecting the former to our standard oxidation conditions and the latter to hydroboration conditions ${ }^{7 \mathrm{~b}}$ This provided homologated aldehyde $\mathbf{6}$ and geminal bis(boronate) $\mathbf{8}$ components that we could then join together under our standard homologative coupling conditions to yield ketone $\mathbf{9}$.

To conclude, we have developed a metal-free homologative cross-coupling reaction of aldehydes and ketones via one-pot boron-Wittig reactions and oxidation of the subsequent vinyl boronate. We have shown that a broad range of functional groups can be tolerated in the carbonyl component and demonstrated that enantiopure aldehydes undergo this reaction without any racemization. Further work on the application of 
this reaction to molecules of interest will be reported in due course.

\section{ASSOCIATED CONTENT}

\section{Supporting Information}

The Supporting Information is available free of charge on the ACS Publications website.

Experimental procedures, characterization data (PDF)

\section{AUTHOR INFORMATION}

\section{Corresponding Author \\ * Email: graham.pattison@warwick.ac.uk}

\section{Author Contributions}

The manuscript was written through contributions of all authors. Notes

The authors declare no competing financial interests

\section{ACKNOWLEDGMENT}

G.P. is a Warwick IAS Global Research Fellow. The authors would like to thank the University of Warwick and Royal Society for Research Grants and the Warwick URSS scheme for a summer bursary (T.C.S.). We thank Teena Rajan (Warwick) for preparation of geminal bis(boron) substrates and Prof. Mike Shipman (Warwick) for advice and useful suggestions.

\section{REFERENCES}

(1) Sun, C.-L.; Shi, Z.-J., Chem. Rev. 2014, 114, 9219-9280.

(2) Roscales, S.; Csaky, A. G., Chem. Soc. Rev. 2014, 43, 8215 8225 .

(3) (a) Barluenga, J.; Tomás-Gamasa, M.; Aznar, F.; Valdés, C., Nature Chem. 2009, 1, 494-499; (b) Mitchell, T. A.; Bode, J. W., J. Am. Chem. Soc. 2009, 131, 18057-18059; (c) Li, X.; Feng, Y.; Lin, L.; Zou, G., J. Org. Chem. 2012, 77, 10991-10995; (d) Allwood, D. M.; Blakemore, D. C.; Brown, A. D.; Ley, S. V., J. Org. Chem. 2014, 79, 328-338; (e) Bering, L.; Antonchick, A. P., Org. Lett. 2015, 17, 3134-3137; (f) Jin, F.; Han, W., Chem. Commun. 2015, 51, $9133-$ 9136; (g) Li, C.; Zhang, Y.; Sun, Q.; Gu, T.; Peng, H.; Tang, W., J. Am. Chem. Soc. 2016, 138, 10774-10777; (h) Roscales, S.; Csaky, A. G., Chem. Commun. 2016, 52, 3018-3021; (i) Ueda, M.; Nakakoji, D.; Kuwahara, Y.; Nishimura, K.; Ryu, I., Tetrahedron Lett. 2016, 57, 4142-4144; (j) Wang, Q.; Tang, X.-Y.; Shi, M., Angew. Chem. Int. Ed. 2016, 55, 10811-10815; (k) Wu, G.; Zhao, X.; Ji, W.; Zhang, Y.; Wang, J., Chem. Commun. 2016, 52, 1961-1963.

(4) Matteson, D. S.; Moody, R. J., J. Am. Chem. Soc. 1977, 99, 3196-3197.

(5) Zhang, Z.-Q.; Yang, C.-T.; Liang, L.-J.; Xiao, B.; Lu, X.; Liu, J.-H.; Sun, Y.-Y.; Marder, T. B.; Fu, Y., Org. Lett. 2014, 16, 63426345.

(6) (a) Ito, H.; Kubota, K., Org. Lett. 2012, 14, 890-893; (b) Atack, T. C.; Cook, S. P., J. Am. Chem. Soc. 2016, 138, 6139-6142.

(7) (a) Nguyen, P.; Coapes, R. B.; Woodward, A. D.; Taylor, N. J.; Burke, J. M.; Howard, J. A. K.; Marder, T. B., J. Organomet. Chem. 2002, 652, 77-85; (b) Endo, K.; Hirokami, M.; Shibata, T., Synlett 2009, 2009, 1331-1335; (c) Feng, X.; Jeon, H.; Yun, J., Angew. Chem. Int. Ed. 2013, 52, 3989-3992; (d) Coombs, J. R.; Zhang, L.; Morken, J. P., J. Am. Chem. Soc. 2014, 136, 16140-16143; (e) Lee, S.; Li, D.; Yun, J., Chem. Asian. J. 2014, 9, 2440-2443; (f) Zuo, Z.; Huang, Z., Org. Chem. Front. 2016, 3, 434-438.

(8) Cho, S. H.; Hartwig, J. F., Chem. Sci. 2014, 5, 694-698.

(9) (a) Abu Ali, H.; Goldberg, I.; Kaufmann, D.; Burmeister, C.; Srebnik, M., Organometallics 2002, 21, 1870-1876; (b) Li, H.; Wang, L.; Zhang, Y.; Wang, J., Angew. Chem. Int. Ed. 2012, 51, 2943-2946; (c) Li, H.; Shangguan, X.; Zhang, Z.; Huang, S.; Zhang, Y.; Wang, J., Org. Lett. 2014, 16, 448-451; (d) Wommack, A. J.; Kingsbury, J. S.,
Tetrahedron Lett. 2014, 55, 3163-3166; (e) Cuenca, A. B.; Cid, J.; Garcia-Lopez, D.; Carbo, J. J.; Fernandez, E., Org. Biomol. Chem. 2015, 13, 9659-9664; (f) Wang, L.; Zhang, T.; Sun, W.; He, Z.; Xia, C.; Lan, Y.; Liu, C., J. Am. Chem. Soc. 2017, 139, 5257-5264.

(10) (a) Endo, K.; Ohkubo, T.; Hirokami, M.; Shibata, T., J. Am. Chem. Soc. 2010, 132, 11033-11035; (b) Endo, K.; Ohkubo, T.; Shibata, T., Org. Lett. 2011, 13, 3368-3371; (c) Lee, J. C. H.; McDonald, R.; Hall, D. G., Nature Chem. 2011, 3, 894-899; (d) Endo, K.; Ishioka, T.; Ohkubo, T.; Shibata, T., J. Org. Chem. 2012, 77, 7223-7231; (e) Endo, K.; Ohkubo, T.; Ishioka, T.; Shibata, T., J. Org. Chem. 2012, 77, 4826-4831; (f) Endo, K.; Kurosawa, F.; Ukaji, Y., Chem. Lett. 2013, 42, 1363-1365; (g) Li, H.; Zhang, Z.; Shangguan, X.; Huang, S.; Chen, J.; Zhang, Y.; Wang, J., Angew. Chem. Int. Ed. 2014, 53, 11921-11925; (h) Potter, B.; Szymaniak, A. A.; Edelstein, E. K.; Morken, J. P., J. Am. Chem. Soc. 2014, 136, 17918-17921; (i) Sun, C.; Potter, B.; Morken, J. P., J. Am. Chem. Soc. 2014, 136, 65346537; (j) Sun, H.-Y.; Kubota, K.; Hall, D. G., Chem. Eur. J. 2015, 21, 19186-19194; (k) Xu, S.; Shangguan, X.; Li, H.; Zhang, Y.; Wang, J., J. Org. Chem. 2015, 80, 7779-7784; (1) Potter, B.; Edelstein, E. K.; Morken, J. P., Org. Lett. 2016, 18, 3286-3289.

(11) (a) Joannou, M. V.; Moyer, B. S.; Goldfogel, M. J.; Meek, S. J., Angew. Chem. Int. Ed. 2015, 54, 14141-14145; (b) Joannou, M. V.; Moyer, B. S.; Meek, S. J., J. Am. Chem. Soc. 2015, 137, 6176-6179; (c) Murray, S. A.; Green, J. C.; Tailor, S. B.; Meek, S. J., Angew. Chem. Int. Ed. 2016, 55, 9065-9069.

(12) (a) Kim, J.; Park, S.; Park, J.; Cho, S. H., Angew. Chem. Int Ed. 2016, 55, 1498-1501; (b) Shi, Y.; Hoveyda, A. H., Angew. Chem. Int. Ed. 2016, 55, 3455-3458; (c) Zhan, M.; Li, R.-Z.; Mou, Z.-D.; Cao, C.-G.; Liu, J.; Chen, Y.-W.; Niu, D., ACS Catal. 2016, 33813386; (d) Zhang, Z.-Q.; Zhang, B.; Lu, X.; Liu, J.-H.; Lu, X.-Y.; Xiao, B.; Fu, Y., Org. Lett. 2016, 18, 952-955.

(13) (a) Ebrahim-Alkhalil, A.; Zhang, Z.-Q.; Gong, T.-J.; Su, W.; Lu, X.-Y.; Xiao, B.; Fu, Y., Chem. Commun. 2016; (b) Park, J.; Lee, Y.; Kim, J.; Cho, S. H., Org. Lett. 2016, 18, 1210-1213; (c) Ahmed, E.-A. M. A.; Lu, X.; Gong, T.-J.; Zhang, Z.-Q.; Xiao, B.; Fu, Y., Chem. Commun. 2017, 53, 909-912; (d) Blair, D. J.; Tanini, D.; Bateman, J. M.; Scott, H. K.; Myers, E. L.; Aggarwal, V. K., Chem. Sci. 2017, 8, 2898-2903; (e) Palmer, W. N.; Zarate, C.; Chirik, P. J., J. Am. Chem. Soc. 2017, 139, 2589-2592.

(14) (a) Matteson, D. S.; Moody, R. J.; Jesthi, P. K., J. Am. Chem. Soc. 1975, 97, 5608-5609; (b) Matteson, D. S.; Moody, R. J., J. Org. Chem. 1980, 45, 1091-1095; (c) Matteson, D. S.; Moody, R. J., Organometallics 1982, 1, 20-28; (d) Endo, K.; Hirokami, M.; Shibata, T., J. Org. Chem. 2010, 75, 3469 - 3472; (e) Endo, K.; Sakamoto, A.; Ohkubo, T.; Shibata, T., Chem. Lett. 2011, 40, 1440-1442; (f) Coombs, J. R.; Zhang, L.; Morken, J. P., Org. Lett. 2015, 17, 17081711; (g) La Cascia, E.; Cuenca, A. B.; Fernández, E., Chem. Eur. J. 2016, 22, 18737-18741.

(15) Lindenschmidt, A., Science of Synthesis. In Science of Synthesis, Brückner, R., Ed. Thieme: Stuttgart, 2007; Vol. 25, p 237.

(16) (a) Hong, K.; Liu, X.; Morken, J. P., J. Am. Chem. Soc. 2014, 136, 10581-10584; (b) Jo, W.; Kim, J.; Choi, S.; Cho, S. H., Angew. Chem. Int. Ed. 2016, 55, 9690-9694.

(17) (a) Brown, H. C.; Imai, T.; Bhat, N. G., J. Org. Chem. 1986, 51, 5277-5282; (b) Desurmont, G.; Dalton, S.; Giolando, D. M.; Srebnik, M., J. Org. Chem. 1996, 61, 7943-7946; (c) Woodward, A. R.; Burks, H. E.; Chan, L. M.; Morken, J. P., Org. Lett. 2005, 7, $5505-$ 5507; (d) Hussain, M. M.; Walsh, P. J., Angew. Chem. Int. Ed. 2010, 49, 1834-1837; (e) Morimoto, M.; Miura, T.; Murakami, M., Angew. Chem. Int. Ed. 2015, 54, 12659-12663; (f) Wang, C.; Wu, C.; Ge, S., ACS Catal. 2016, 6, 7585-7589.

(18) More details on reaction optimization are available in the Supporting Information.

(19) (a) Gillis, E. P.; Burke, M. D., J. Am. Chem. Soc. 2007, 129, 6716-6717; (b) Burns, M.; Essafi, S.; Bame, J. R.; Bull, S. P.; Webster, M. P.; Balieu, S.; Dale, J. W.; Butts, C. P.; Harvey, J. N.; Aggarwal, V. K., Nature 2014, 513, 183-188; (c) Battilocchio, C.; Feist, F.; Hafner, A.; Simon, M.; Tran, D. N.; Allwood, D. M.; Blakemore, D. C.; Ley, S. V., Nature Chem. 2016, 8, 360-367. 
(20) Aromatic aldehydes were also sensitive to other decomposition pathways on oxidation, including C-C cleavage processes. For more details, see the Supporting Information. 